Research Article

\title{
Variability of Ground Motion Amplitudes Recorded in Bucharest Area during Vrancea Intermediate-Depth Earthquakes
}

\author{
Florin Pavel \\ Department of Reinforced Concrete Structures, Technical University of Civil Engineering Bucharest, Bucharest, Romania \\ Correspondence should be addressed to Florin Pavel; florin.pavel@utcb.ro
}

Received 23 July 2021; Revised 25 August 2021; Accepted 9 October 2021; Published 3 November 2021

Academic Editor: Wahyu Caesarendra

Copyright ( 92021 Florin Pavel. This is an open access article distributed under the Creative Commons Attribution License, which permits unrestricted use, distribution, and reproduction in any medium, provided the original work is properly cited.

\begin{abstract}
This study focuses on the assessment of the correlation and variability of ground motion amplitudes recorded in Bucharest area during Vrancea intermediate-depth earthquakes from a database of 119 pairs of horizontal components. Empirical models for the evaluation of the peak ground velocity and displacement from spectral accelerations are proposed in this study. The distribution of the shear wave velocities from 41 boreholes at specific depths appears to follow a normal probability distribution. The analysis performed in this study has also shown that the variability of peak ground velocities and displacements does not appear to be influenced by the earthquake magnitude. In addition, it was observed that the variability in terms of shear wave velocities at specific depths is smaller than the variability of the spectral amplitudes of the recorded ground motions. The empirical siteamplification factors from the Eurocode 8 draft fail to capture the long-period spectral amplifications observed in Bucharest area during large magnitude Vrancea intermediate-depth earthquakes.
\end{abstract}

\section{Introduction}

Significant long-period spectral amplifications have been observed in Bucharest, the capital city of Romania, during large magnitude Vrancea intermediate-depth earthquakes occurring in the past 40 years [1,2]. A combination of source and site effects appears to be reason for the occurrence of such amplifications [3-6] during large magnitude earthquakes. Unfortunately, no ground motion was recorded during the largest seismic event of the past century, the November 1940 Vrancea earthquake, and thus, the abovemade observation cannot be validated. In addition, besides the long-period amplifications, pulse-like ground motion recordings were observed at various seismic stations within the Bucharest area during the last three significant Vrancea intermediate-depth earthquakes in 1977, 1986, and 1990 [7]. The single free-field ground motion recorded in Bucharest during the major 1977 Vrancea earthquake is characterised by a very strong pulse.

Recently, Olteanu and Vacareanu [8] have developed an empirical model for the prediction of spectral displacements generated by Vrancea intermediate-depth earthquakes.
From the point of view of spectral accelerations, Vacareanu et al. [9] have developed a ground motion model for the prediction of spectral acceleration from Vrancea intermediate-depth earthquakes. The soil conditions are defined in both models using the criteria from the current version of the Eurocode 8 [10].

Pavel et al. [11] have proposed a model for the evaluation of ground motion amplitudes in Bucharest area using a database of natural and simulated recordings. The site-response analysis performed in the study of Pavel et al. [12] has shown that the median site amplifications decrease with the increase of the input peak ground acceleration for spectral periods of up to $2.0 \mathrm{~s}$, while for longer periods, the median site amplifications increase denoting nonlinear soil behaviour.

This study focuses on the evaluation of the variability in terms of ground motion amplitudes and comparison with the variability of the shear wave velocities in the upper $50 \mathrm{~m}$ of soil deposits as obtained from 41 boreholes in the Bucharest area. In addition, site-specific empirical relations for the evaluation of the peak ground velocity and displacement from the spectral accelerations are also proposed 
in this study. The site amplifications computed from the recorded ground motions are also compared with the empirical ones from the recent Eurocode 8 draft [13].

\section{Ground Motion Database}

The database used in this study consists of 119 pairs of horizontal ground motion recordings from 11 Vrancea intermediate-depth earthquakes occurring in the period 1977-2013 with moment magnitudes $M_{W}$ in the range $5.0-7.4$ and focal depths in the range $87-154 \mathrm{~km}$. The characteristics of the seismic events, the number of ground motion recordings, epicentral distance range, and peak ground acceleration (PGA) range for each earthquake are reported in Table 1. A reverse faulting mechanism with the rupture propagating in the NE-SW direction [14] (for most of the earthquakes and for the largest ones) or in the NW-SE direction is observed for all the seismic events in the database. A part of this database has been used in previous studies (e.g., [15]) and has been extended for this research. The processing of the digital ground motion recordings was performed using the procedures from the literature $[16,17]$. In the case of the analogue recordings from older seismic events, no processing was performed since only the processed waveforms were available for this study. The analogue waveforms were processed using a Ormsby filter with the low-pass frequency of $0.20-0.25 \mathrm{~Hz}$ and a high-pass frequency of $25-28 \mathrm{~Hz}$ [18].

The distribution of the epicentral distance and peak ground acceleration of the ground motion recordings with the earthquake magnitude is illustrated in Figure 1.

\section{Evaluation of Ground Motion Amplitudes}

The normalised acceleration response spectra as a function of the earthquake magnitude are analysed in Figure 2. The occurrence of significant long-period spectral amplifications for earthquakes with magnitudes larger than 7.0 is noteworthy from Figure 2. However, this aspect needs further validation from future seismic events in order to check the impact of the source-site distance on the spectral amplifications, besides the influence of the earthquake magnitude.

The variation of the peak ground velocity and peak ground displacement with the earthquake magnitude is analysed in Figure 3. A significant increase of the mean peak ground velocity and peak ground displacement for moment magnitudes larger than 6.4 can be inferred from Figure 3 .

A comparison between the maximum spectral accelerations from the ground motion recordings in the database and the design acceleration response spectra from the current Romanian seismic code P100-1/2013 [19] and from the current Eurocode 8 [10] are illustrated in Figure 4. A site class $\mathrm{C}$ is assumed for Bucharest in order to evaluate the design acceleration response spectrum according to Eurocode 8 [10]. It can be observed that the design acceleration response spectrum has been exceeded by the recordings in the short-period range (ground motions recorded during the $M_{W} 6.9$ Vrancea intermediate-depth earthquake of May 1990). However, for the medium- and long-period range, the spectral accelerations from the recorded ground motions are well below the design values.

\section{Correlation of Spectral Accelerations with Peak Ground Velocity and Displacement}

While spectral accelerations are important for the evaluation of the seismic fragility and risk of structures and buildings, the peak ground velocity and displacement are employed in the seismic risk assessment of distributed pipe networks (gas, water, and sewage) [20]. Since, the spectral accelerations are relatively easily obtained, there are a number of studies in the literature which have developed empirical relations between the spectral amplitudes and the peak ground motion values. Pavel and Lungu [21] have evaluated the relation between various frequency content parameters and the spectral accelerations. The following empirical relation between the peak ground velocity and the spectral acceleration at $1.0 \mathrm{~s}\left(S A_{1.0}\right)$ was proposed [21]:

$$
\mathrm{PGV}=\frac{S A_{1.0}}{8}
$$

Another simple relation for the prediction of the peak ground velocity from spectral acceleration was proposed by Bommer and Alarcon [22] and is given as follows:

$$
\mathrm{PGV}=\frac{S A_{0.5}}{20} \text {. }
$$

Booth [23] and Malhotra [24] have proposed empirical relations for the computation of the peak values of the ground motion (acceleration, velocity, and displacement) using the maximum acceleration, velocity, and displacement spectral ordinates. The empirical relations obtained using the ground motion dataset from this study and the ones proposed by Booth [23], Malhotra [24] and Pavel et al. [15] are reported in Table 2 . It can be observed that there are significant differences between the relations reported in Pavel et al. [15] and those proposed in this study. The reason for these differences is due to the fact that, in this study, only ground motions recorded in Bucharest area are employed, while in the study of Pavel et al. [15], ground motions recorded all over the Romanian territory were used.

The correlation between the peak ground velocity (PGV) and peak ground displacement (PGD) and the spectral accelerations for the ground motion recordings in the database is illustrated in Figure 5. The maximum correlation coefficient between the PGV and PGD and the spectral accelerations are observed at $T=1.0 \mathrm{~s}$ and $T=2.0 \mathrm{~s}$, respectively.

Subsequently, based on the previously computed correlation coefficients, the following empirical models for the evaluation of PGV and PGD from spectral accelerations for ground motions recorded in Bucharest area are proposed:

$$
\begin{aligned}
& P G V=\frac{S A_{1.0}}{10}, \\
& P G D=\frac{S A_{2.0}}{28} .
\end{aligned}
$$


TABLE 1: Characteristics of the earthquakes in the database.

\begin{tabular}{|c|c|c|c|c|c|c|c|}
\hline No. & Date & $\begin{array}{c}\text { Moment magnitude } \\
\left(M_{W}\right)\end{array}$ & $\begin{array}{l}\text { Focal depth } \\
(\mathrm{km})\end{array}$ & $\begin{array}{c}\text { Focal } \\
\text { mechanism }\end{array}$ & $\begin{array}{l}\text { No. of ground motion } \\
\text { recordings }\end{array}$ & $\begin{array}{l}\text { Epicentral distance } \\
\text { range }(\mathrm{km})\end{array}$ & $\begin{array}{c}\text { PGA } \\
\text { range }(g)\end{array}$ \\
\hline 1 & 04.03 .1977 & 7.4 & 94 & Reverse & 1 & 101 & 0.21 \\
\hline 2 & 30.08 .1986 & 7.1 & 131 & Reverse & 14 & $101-135$ & $0.05-0.16$ \\
\hline 3 & 30.05 .1990 & 6.9 & 91 & Reverse & 13 & $145-178$ & $0.06-0.22$ \\
\hline 4 & 31.05 .1990 & 6.4 & 87 & Reverse & 9 & $161-181$ & $0.01-0.04$ \\
\hline 5 & 28.04.1999 & 5.3 & 151 & Reverse & 6 & $90-128$ & $0.01-0.04$ \\
\hline 6 & 06.04 .2000 & 5.0 & 143 & Reverse & 3 & $123-163$ & $0.01-0.02$ \\
\hline 7 & 27.10 .2004 & 6.0 & 105 & Reverse & 21 & $149-168$ & $0.02-0.06$ \\
\hline 8 & 14.05 .2005 & 5.5 & 149 & Reverse & 16 & 109-149 & $<0.01$ \\
\hline 9 & 18.06.2005 & 5.2 & 154 & Reverse & 16 & $120-160$ & $<0.01$ \\
\hline 10 & 25.04.2009 & 5.4 & 110 & Reverse & 10 & $115-155$ & $0.01-0.03$ \\
\hline 11 & 06.10 .2013 & 5.2 & 135 & Reverse & 10 & $113-154$ & $0.01-0.04$ \\
\hline
\end{tabular}

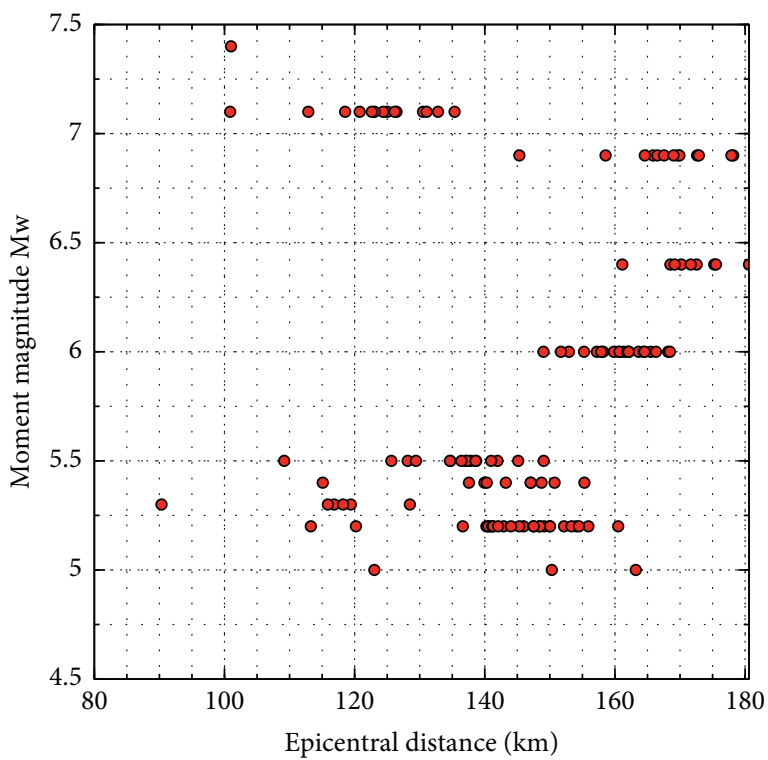

(a)

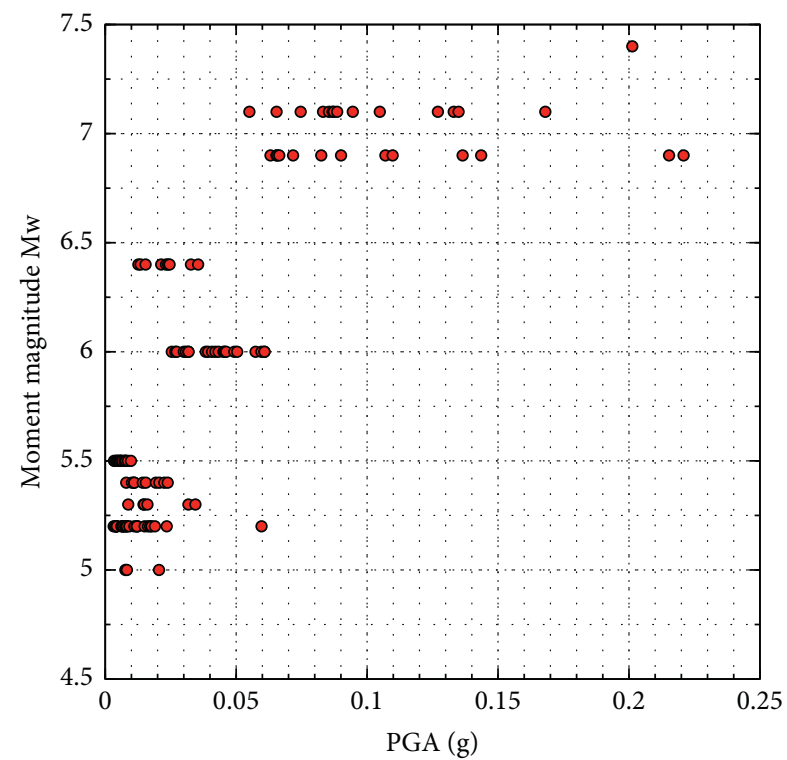

(b)

FIGURE 1: Distribution of the epicentral distance and peak ground acceleration with the earthquake magnitude for the database.

The relation between the observed and the empirical peak ground velocities and displacements is illustrated in Figure 6.

Subsequently, the peak ground velocity and displacement are evaluated using relations (3) and (4) from the spectral accelerations obtained using the ground motion model of Pavel et al. [11]. A comparison between the observed and empirical peak ground velocities and displacements is shown in Figure 7. It can be observed that there is a very good fit between the observed and the empirical peak ground velocities and displacements, with the exception of the $M_{\mathrm{W}} 7.11986$ Vrancea earthquake.

The coefficients of variation for the spectral accelerations observed during the four largest magnitude earthquakes in the database are analysed in Figure 8. It can be observed that the same trend of variability is observed for all four earthquakes in the sense that the largest variabilities are observed for short periods and for long periods, as well. The large variability associated with the long periods may also be due to the processing of the ground motion recordings.
Figure 9 compares the variability for the peak ground velocity and displacement as a function of the earthquake magnitude for the four largest magnitude events in the database. It can be observed that the variability associated with both the peak ground velocity and displacement has the same order of magnitude and does not appear to be influenced by the earthquake magnitude.

A comparison between the variability of the spectral accelerations observed at seismic stations within Bucharest area during the Vrancea intermediate-depth earthquake of April $2009\left(M_{W}=5.4\right.$ and $\left.h=110 \mathrm{~km}\right)$ and during the Vrancea crustal earthquake of November $2014\left(M_{W}=5.4\right.$ and $h=41 \mathrm{~km}$ ) is shown in Figure 10. The 2014 event is the largest event which occurred in the Vrancea crustal seismic zone (which overlaps the Vrancea intermediate-depth zone) in the past 60 years. Since it is a crustal event, it was not mentioned in Table 1. The evaluation of the variability of the spectral accelerations for the 2014 event is performed using the data from 8 seismic stations in Bucharest area (as compared to 10 for the 2009 intermediate-depth event). It 


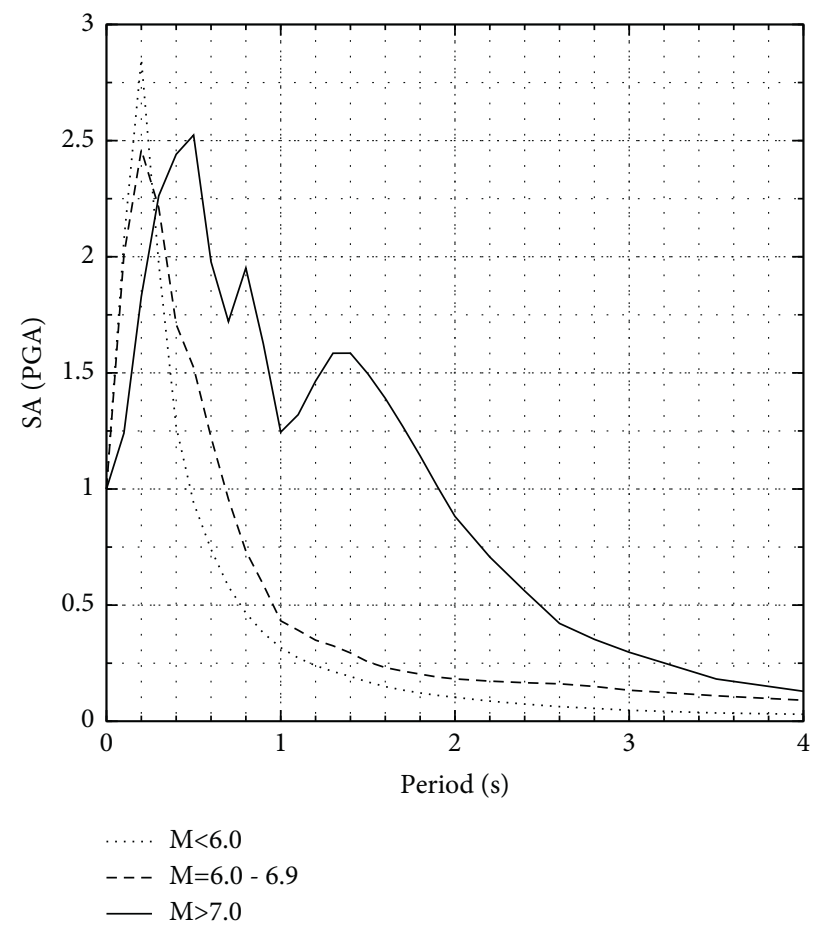

FIgURE 2: Mean normalised acceleration response spectra as a function of the earthquake magnitude.

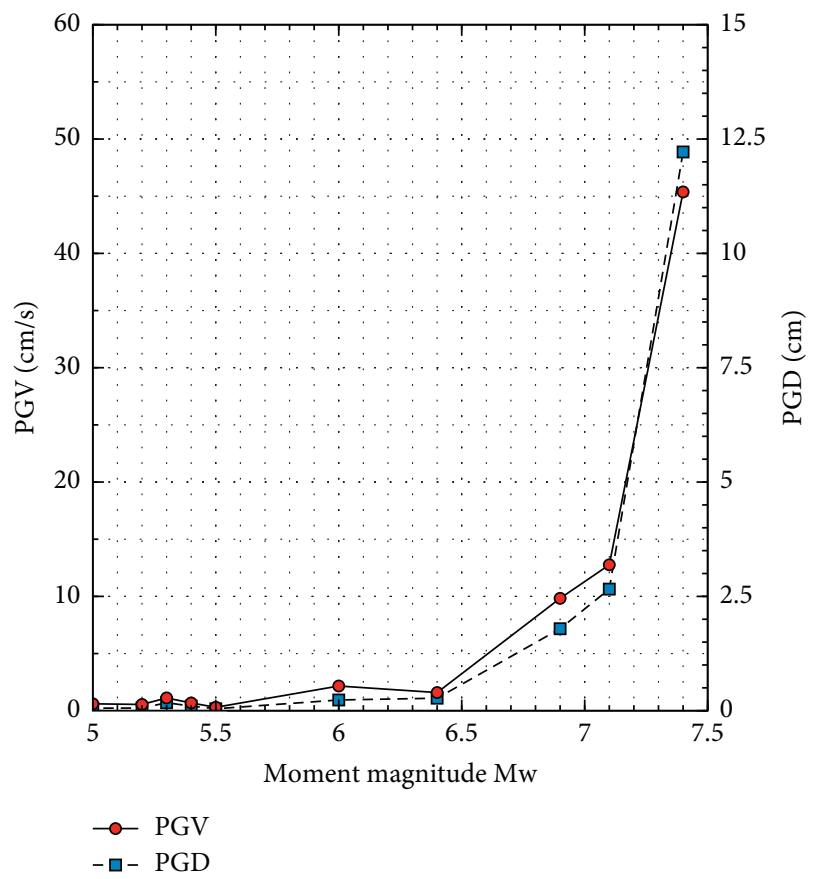

FIGURE 3: Variation with the earthquake magnitude of the mean peak ground velocity and peak ground displacement. 


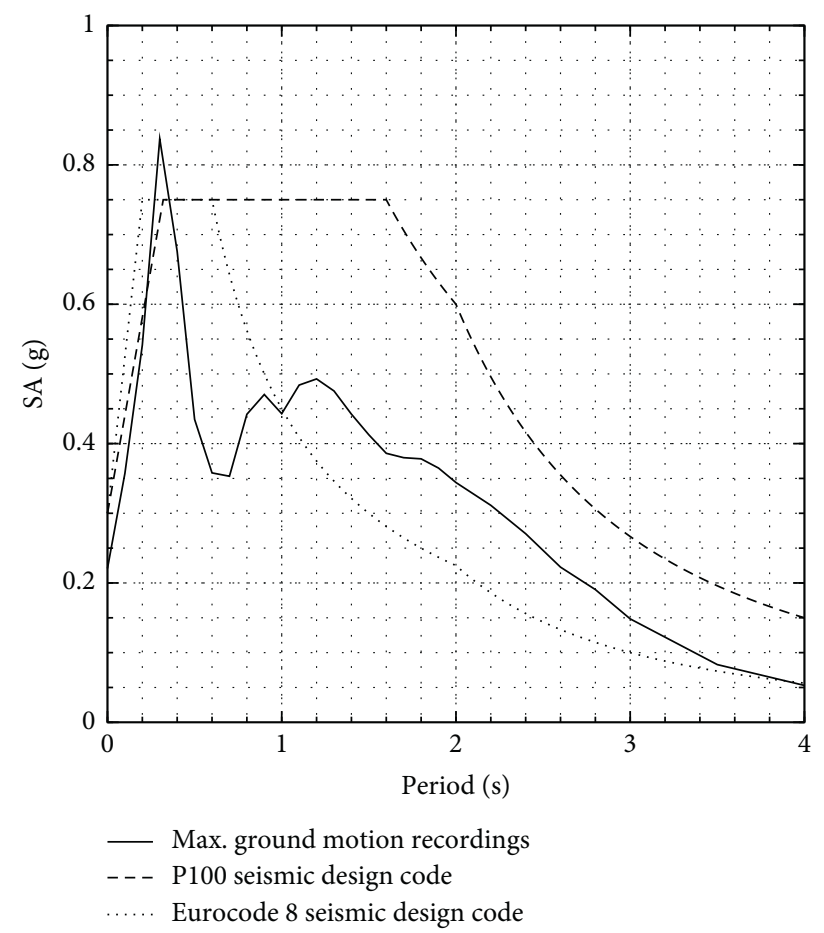

Figure 4: Comparison between the maximum spectral accelerations of the ground motion recordings in the database and the design spectral accelerations from the codes P100-1/2013 [19] and Eurocode 8 [10].

TABle 2: Comparison between the empirical relations for the computation of the peak ground acceleration, velocity, and displacement from various studies.

\begin{tabular}{|c|c|c|c|c|}
\hline \multirow[b]{2}{*}{ Parameter } & \multicolumn{4}{|c|}{ Relation } \\
\hline & Booth [23] & $\begin{array}{c}\text { Malhotra } \\
\text { [24] }\end{array}$ & $\begin{array}{l}\text { Pavel et al. } \\
{[15]}\end{array}$ & This study \\
\hline PGA & $S A_{\max } / 2.65$ & $S A_{\max } / 2.14$ & $S A_{\max } / 2.31$ & $S A_{\max } / 2.91$ \\
\hline PGV & $S V_{\max } / 2.30$ & $S V_{\max } / 1.63$ & $S V_{\max } / 1.59$ & $S V_{\max } / 2.38$ \\
\hline PGD & $\begin{array}{c}S D_{\max } / \\
2.30\end{array}$ & $S D_{\max } / 1.84$ & $S D_{\max } / 1.50$ & $\begin{array}{c}S D_{\max } / \\
1.86\end{array}$ \\
\hline
\end{tabular}

can be observed that the spectral amplifications are larger for the crustal event, while the variability of the spectral accelerations is larger for the intermediate-depth earthquake of April 2009.

\section{Variability of the Characteristics of the Soil Profiles}

This section focuses on the assessment of the variability of the characteristics of the soil profiles within Bucharest area, namely, the variability in the shear wave velocities. The variability of the shear wave velocity in the upper $50 \mathrm{~m}$ of soil deposits is evaluated by combining the data collected by Bala et al. [25, 26], Calarasu [27], Calarasu et al. [28], and Lungu et al. [29]. The position of the available 41 boreholes and of the recording seismic stations is illustrated in Figure 11. It

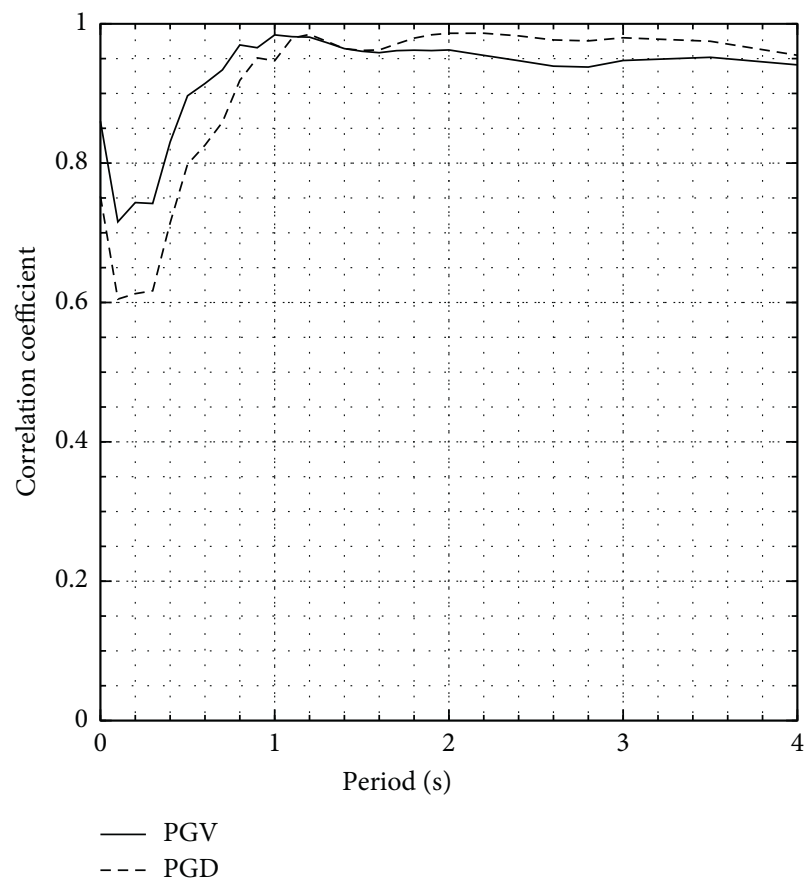

FIGURE 5: Correlation between the peak ground velocity and peak ground displacement and the spectral accelerations.

can be observed that the recording seismic stations are more spread as compared to the positions of the boreholes.

The mean value of the shear wave velocity and the coefficient of variation of the shear wave velocities for the upper $50 \mathrm{~m}$ of soil deposits are illustrated in Figure 12. The 


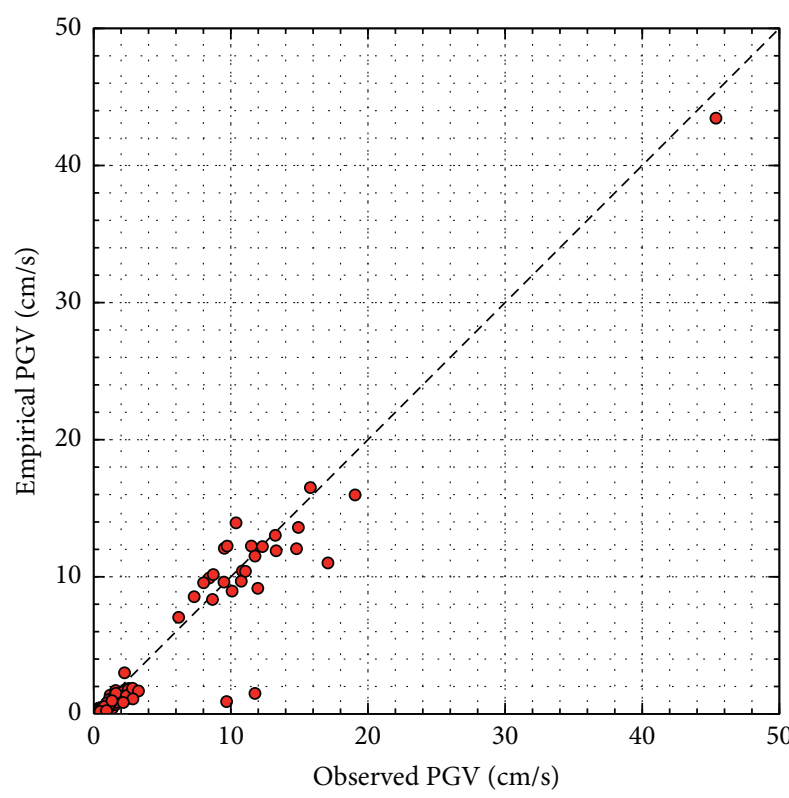

(a)

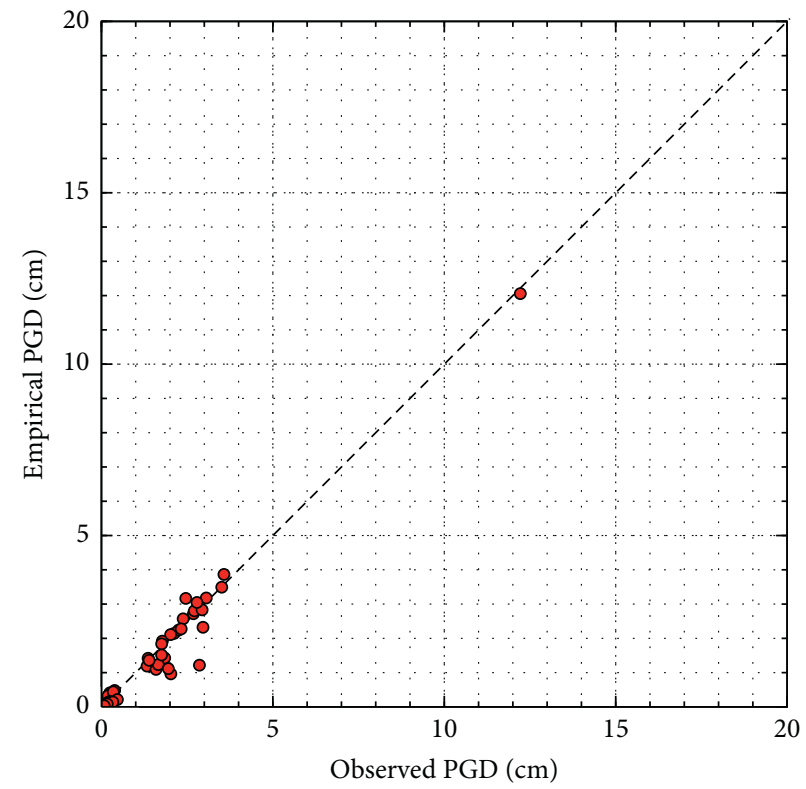

(b)

FIGURE 6: Relation between observed and empirical values for (a) PGV (correlation coefficient $=0.97$ ) and (b) PGD (correlation coefficient $=0.99$ ).

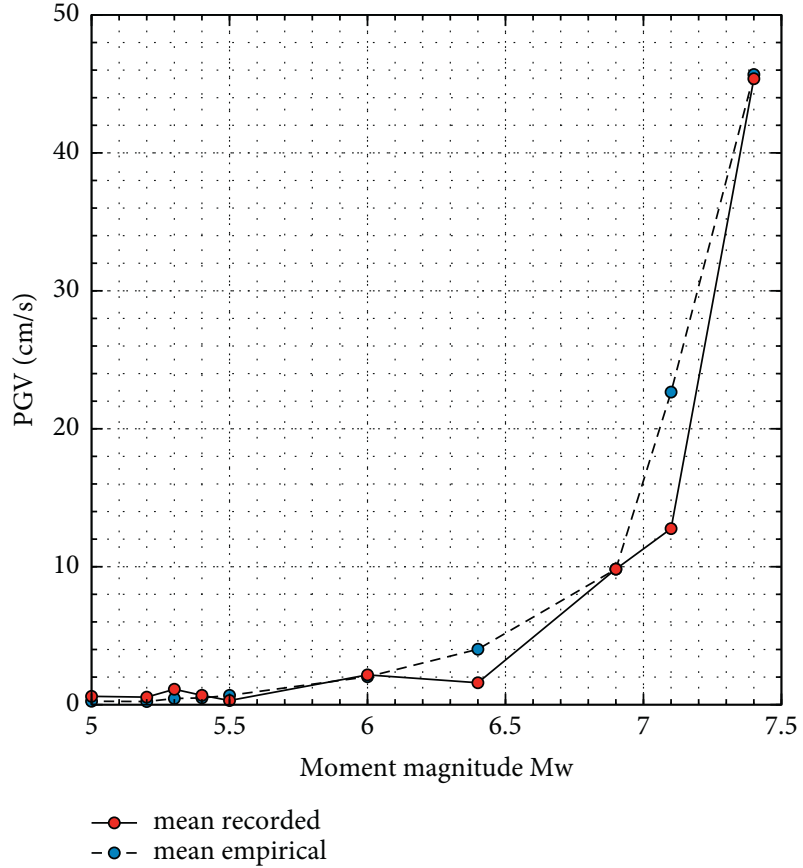

(a)

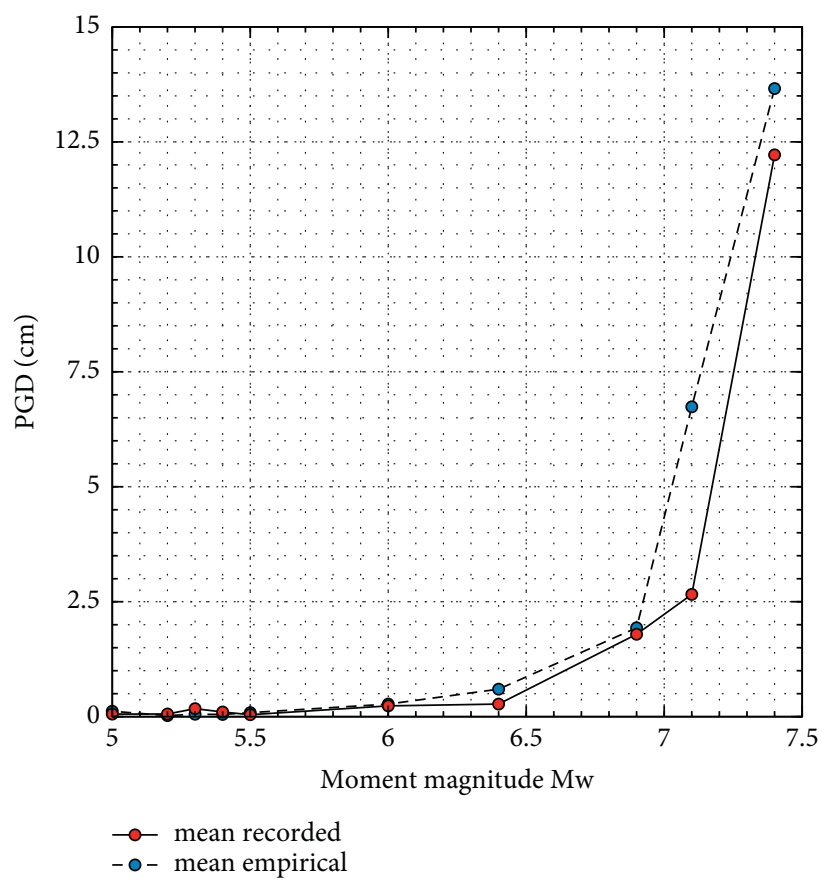

(b)

FIGURE 7: Variation with the earthquake magnitude of the mean observed and predicted (a) peak ground velocities and (b) peak ground displacements.

depth of $50 \mathrm{~m}$ was chosen since a significant number of boreholes (about half of the available 41) reached this depth and only a limited number extended to larger depths. A logarithmic fit is proposed on the mean shear wave velocity. The proposed relation (valid up to a depth of $50 \mathrm{~m}$ ) is mean shear wave velocity $=61.58 \cdot \ln ($ depth $)+147$.

From Figure 12, it can be observed that the proposed logarithmic equation fits quite well the mean shear wave velocity up to $50 \mathrm{~m}$. It can also be observed that the 


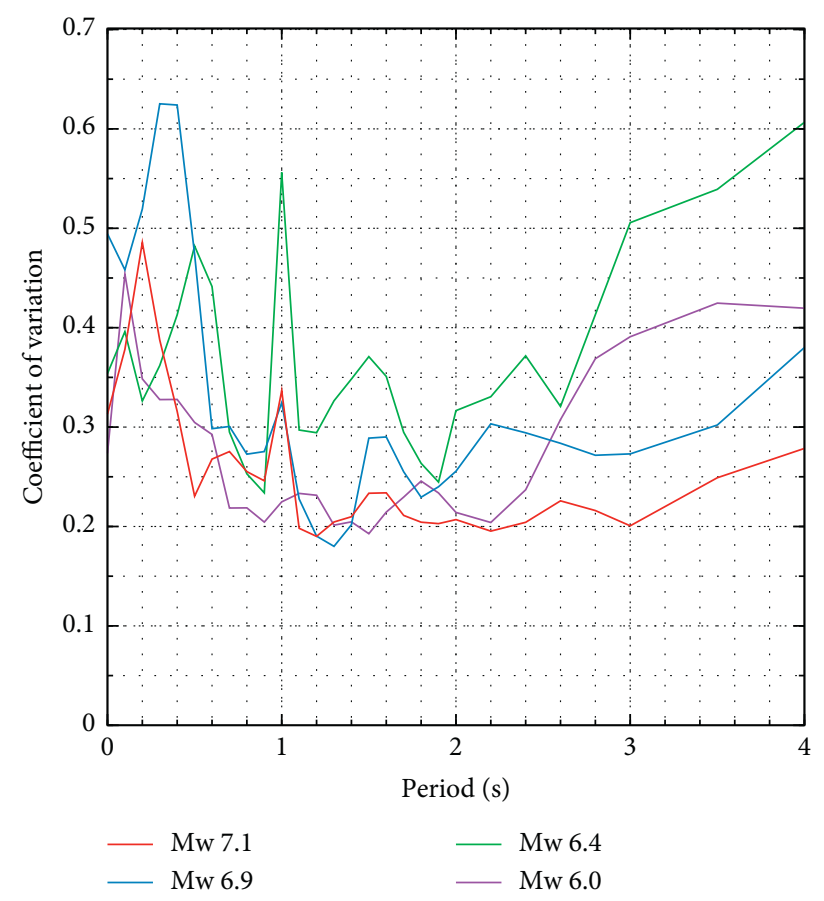

FIGURE 8: Coefficients of variation for the spectral accelerations as a function of the earthquake magnitude.

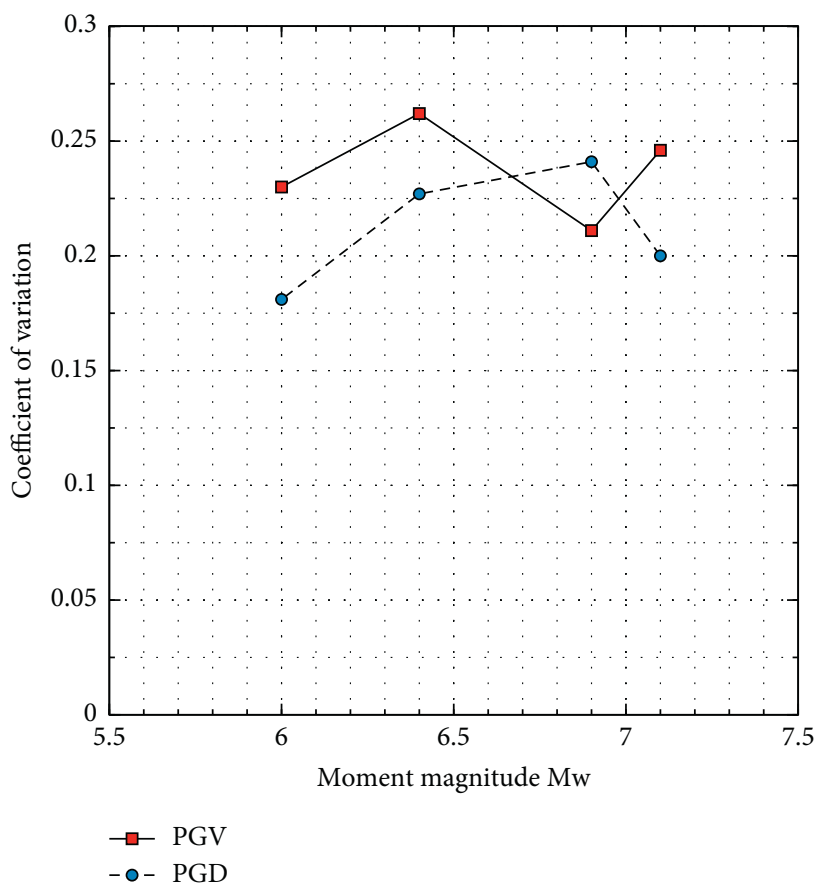

FIgURE 9: Comparison of the coefficients of variation for the peak ground velocity and displacement as a function of the earthquake magnitude.

coefficient of variation of the shear wave velocity decreases with the depth, reaching a value of 0.1 at $50 \mathrm{~m}$. In the top $10 \mathrm{~m}$ of soil layers, the values of the coefficient of variation are of about $0.2-0.25$.
The relative frequency of the shear wave velocities at three depth levels, $10 \mathrm{~m}, 30 \mathrm{~m}$, and $50 \mathrm{~m}$, respectively, is illustrated in Figure 13. On the three relative frequency histograms from Figure 13 are superimposed the corresponding normal 


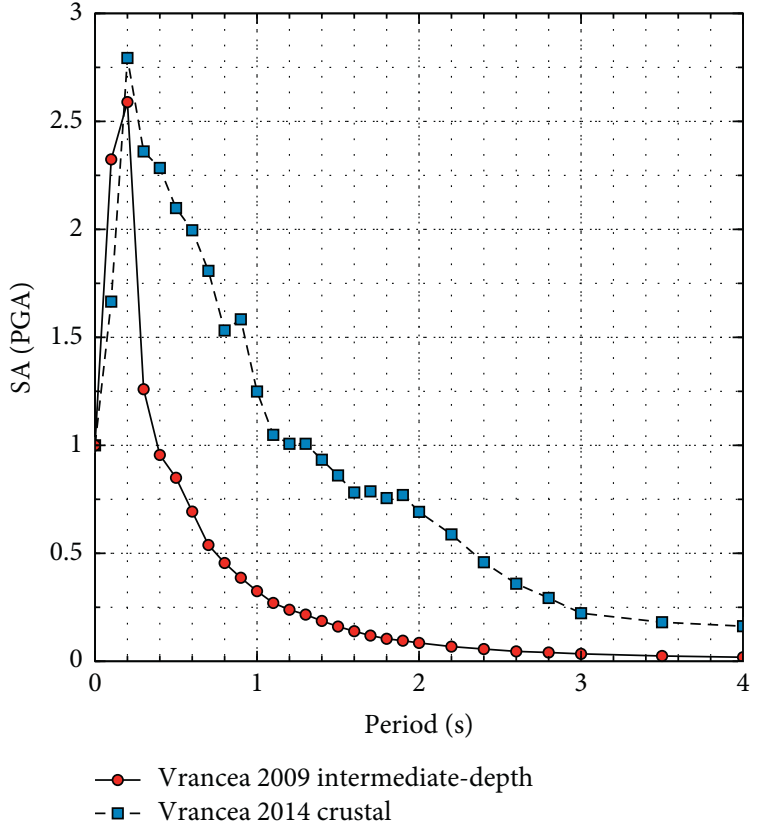

(a)

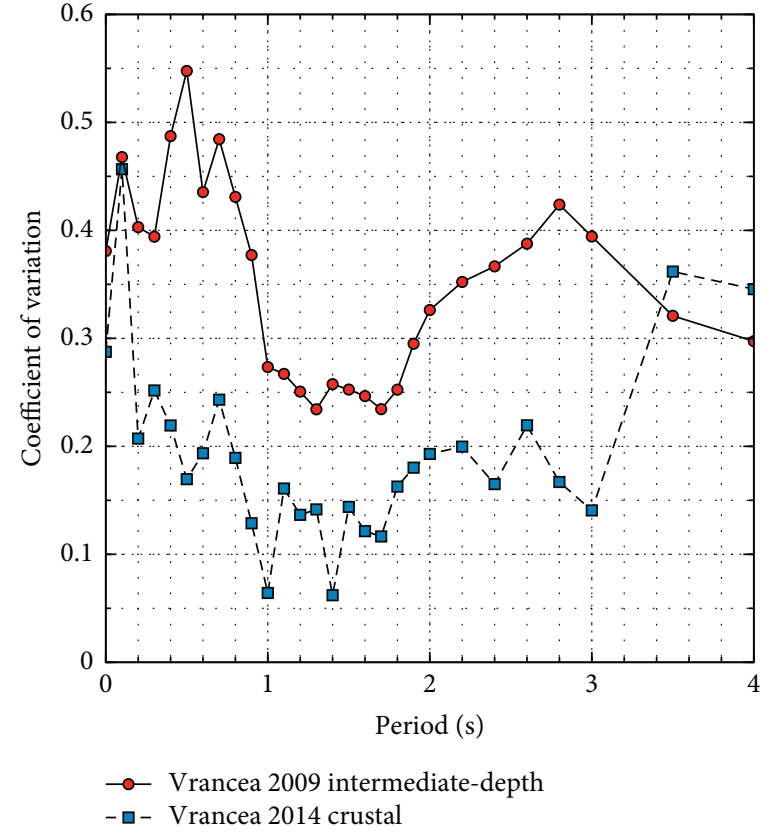

(b)

FiguRE 10: Mean normalised acceleration response spectra and coefficients of variation for the spectral accelerations for the Vrancea intermediate-depth earthquake of April 2009 and for the Vrancea crustal earthquake of November 2014.

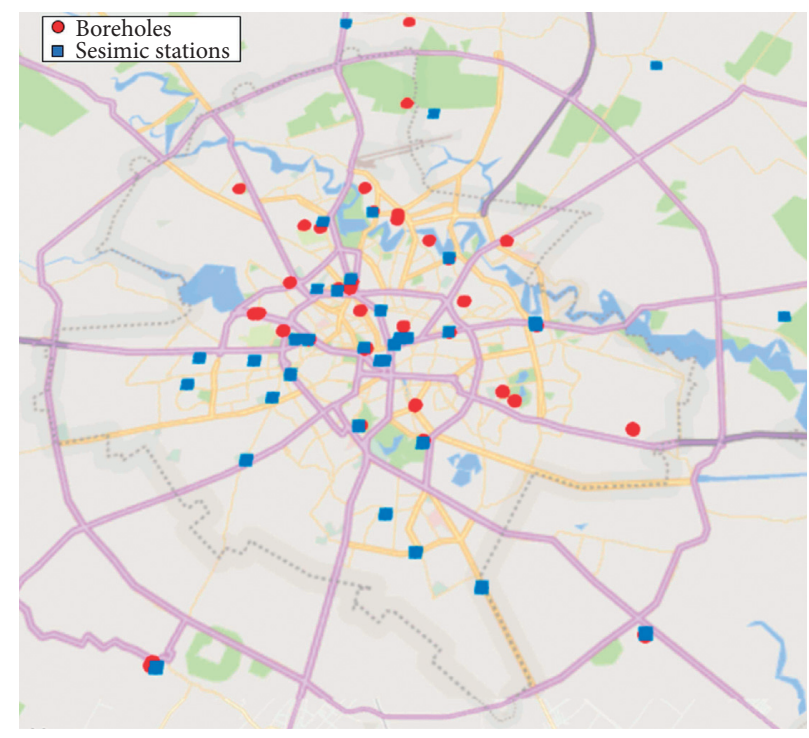

Figure 11: Position of boreholes and of seismic stations in Bucharest area used in this study.

probability plots. For all three depth levels $(10 \mathrm{~m}, 30 \mathrm{~m}$, and $50 \mathrm{~m}$ ), three statistical tests (Kolmogorov-Smirnov, Chisquared, and Anderson-Darling) did not reject the normality assumption for significance levels in the range 0.01-0.20. The mean and standard deviation necessary for computing the normal probability distribution functions shown in Figure 13 are given in Table 3.

The mean and the standard deviation of the shear wave velocity measured in the upper $30 \mathrm{~m}$ and $50 \mathrm{~m}$, respectively, of soil deposits are reported in Table 3 . The decrease with the 


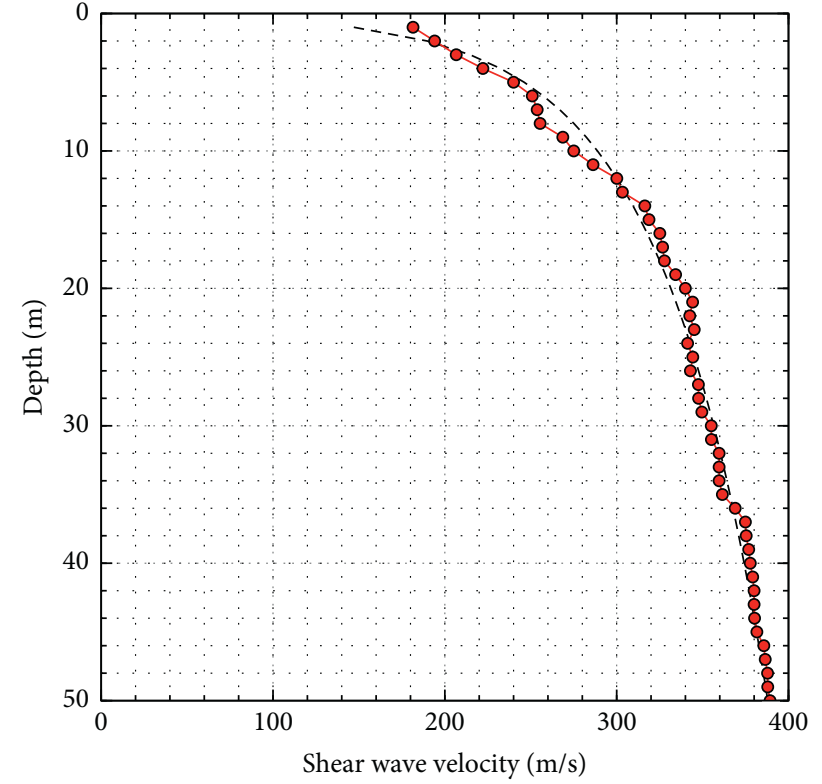

- Mean value

- - Fit

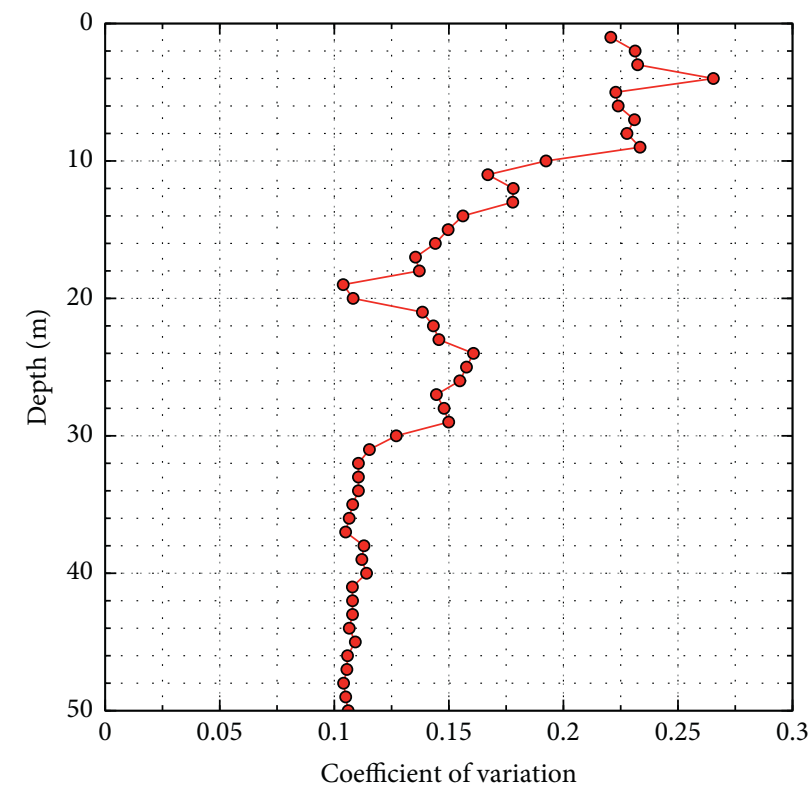

(b)

Figure 12: (a) Mean shear wave velocity as a function of the depth for boreholes in Bucharest area. (b) Coefficient of variation of the shear wave velocity as a function of the depth for boreholes in Bucharest area.

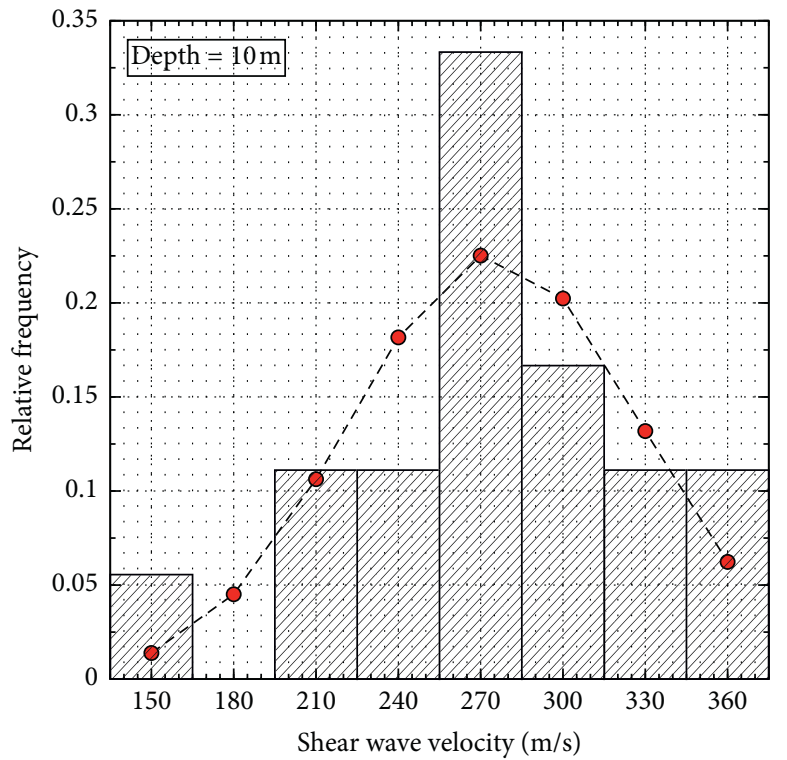

(a)

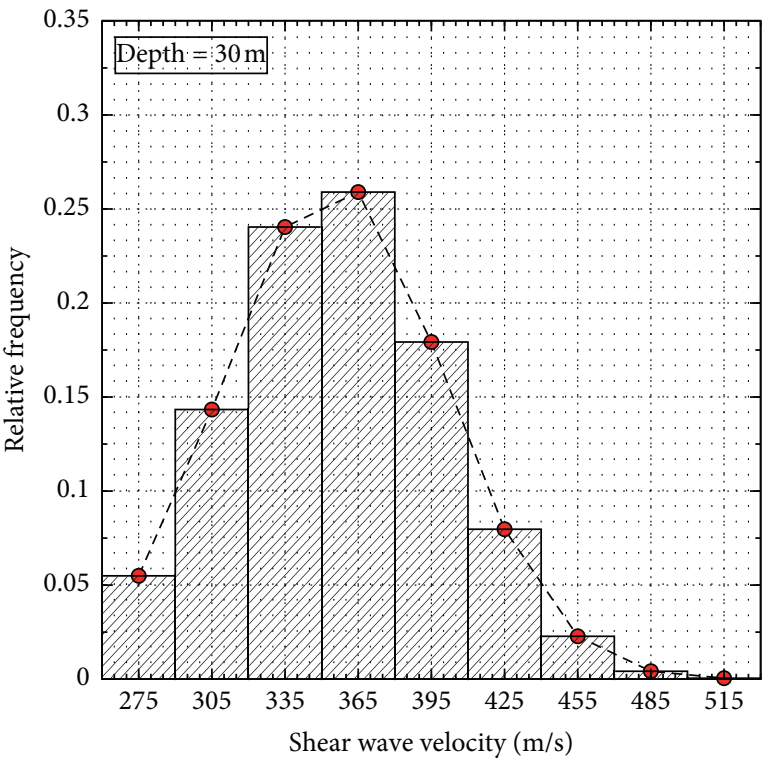

(b)

Figure 13: Continued. 


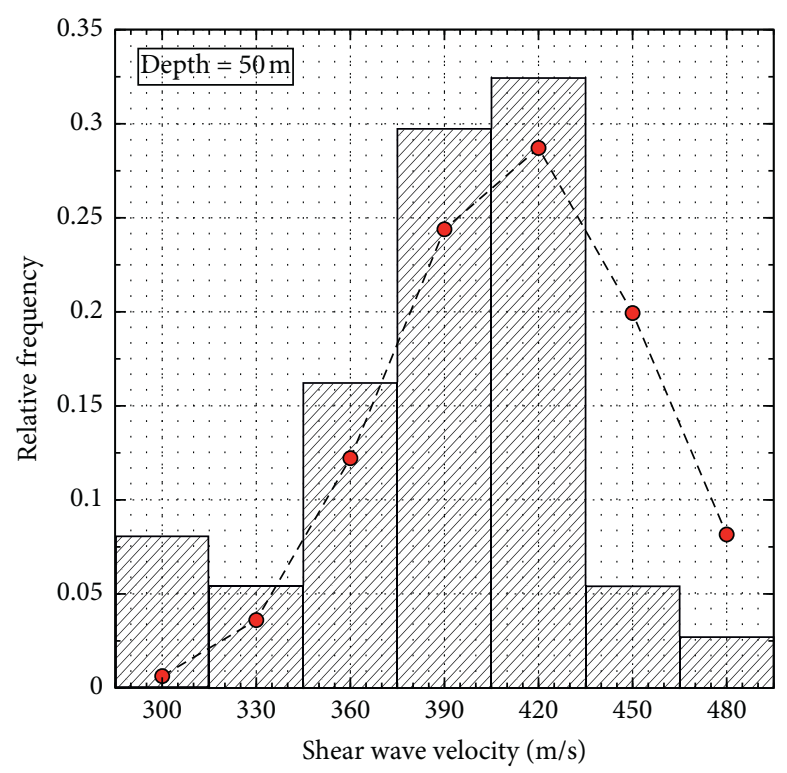

(c)

Figure 13: Relative frequency histograms of the shear wave velocities at (a) depth $=10 \mathrm{~m}$, (b) depth $=30 \mathrm{~m}$, and (c) depth $=50 \mathrm{~m}$. Normal probability distribution functions shown with dashed lines are superimposed on each histogram.

TABLE 3: Mean and standard deviation of the shear wave velocities at depths of $10 \mathrm{~m}, 30 \mathrm{~m}$, and $50 \mathrm{~m}$.

\begin{tabular}{lcc}
\hline Depth $(\mathrm{m})$ & Mean shear wave velocity $(\mathrm{m} / \mathrm{s})$ & Standard deviation of the shear wave velocity $(\mathrm{m} / \mathrm{s})$ \\
\hline 10 & 275 & 53 \\
30 & 355 & 45 \\
50 & 389 & 41 \\
\hline
\end{tabular}

depth of the standard deviation of the shear wave velocity can also be observed from Table 4 which provides the mean shear wave velocity and standard deviation for the upper $30 \mathrm{~m}$ and $50 \mathrm{~m}$, respectively, of soil deposits.

\section{Assessment of Empirical Site Amplifications}

The draft of the future version of the Eurocode 8 [30] proposes a new site classification and new site-amplification factors [13] as compared to the current version [10]. Based on the criteria from Paolucci et al. [13] for the depth to the seismic bedrock (an assumed value of $250 \mathrm{~m}$ ) and shear wave velocity (an assumed value of $300 \mathrm{~m} / \mathrm{s}$ ), a site class $\mathrm{F}$ can be inferred for Bucharest. Subsequently, the ground motion amplitudes for four earthquake scenarios are evaluated considering the ground motion model developed by Abrahamson et al. [31] for rock conditions and the site-amplification factors of Paolucci et al. [13]. The computations are performed for the earthquake scenarios corresponding to the Vrancea seismic events of March $1977\left(M_{W}=7.4, h=94 \mathrm{~km}, d=100 \mathrm{~km}\right)$, August $1986\left(M_{W}=7.1, h=131 \mathrm{~km}, d=120 \mathrm{~km}\right)$, May 1990
$\left(M_{W}=6.9, \quad h=91 \mathrm{~km}, \quad d=160 \mathrm{~km}\right), \quad$ and October 2004 $\left(M_{W}=6.0, h=105 \mathrm{~km}, d=160 \mathrm{~km}\right)$. The median spectral accelerations computed from all the ground motions recorded in Bucharest area during each event are compared with the median spectral accelerations obtained for the same events from the ground motion model by Abrahamson et al. [31] for rock conditions and the site-amplification factors by Paolucci et al. [13] for site class F. The ground motion model of Abrahamson et al. [31] is also employed in the European Seismic Hazard Model 2020. The results of the comparisons are illustrated in Figure 14. The procedure for constructing the design response spectra is given in [30], and it involves the evaluation of the ground motion for rock conditions, which has to be subsequently amplified considering the soil-dependent site amplifications in order to evaluate the sitespecific surface level ground motion. It can be observed from Figure 14, that, on the one hand, the design response spectra constructed according to the abovementioned procedure fail to capture the long-period spectral amplifications occurring during large magnitude Vrancea intermediate-depth earthquakes and on the other hand fail to capture the significant 


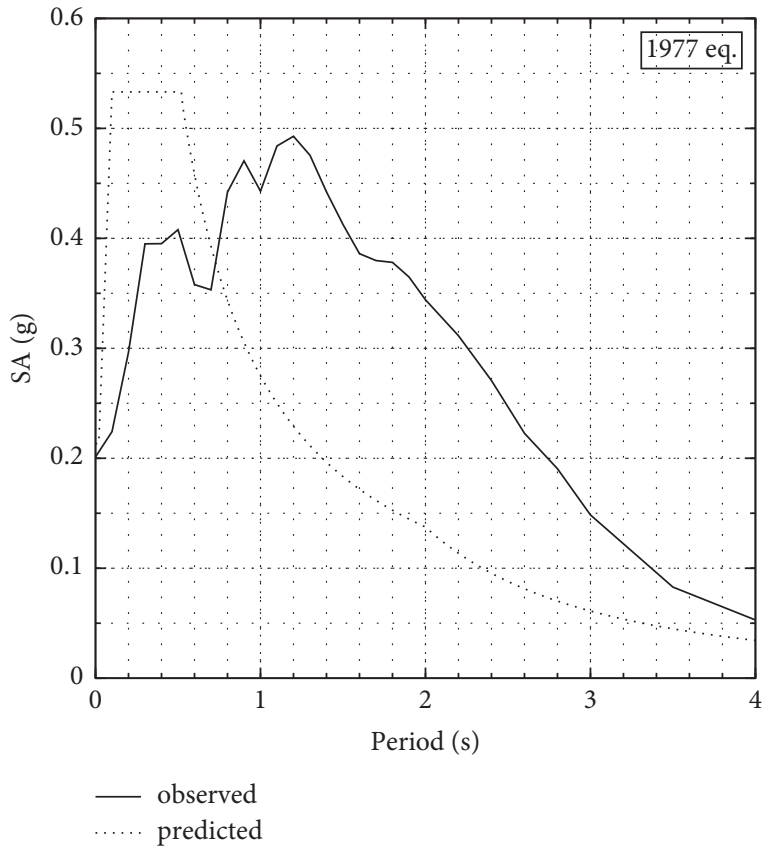

(a)

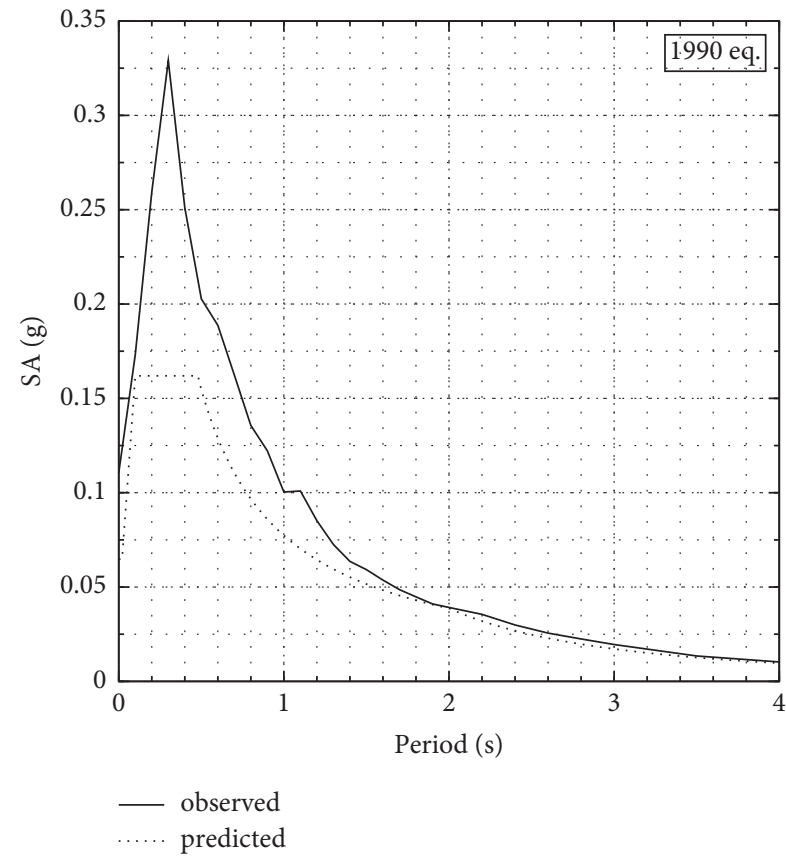

(c)

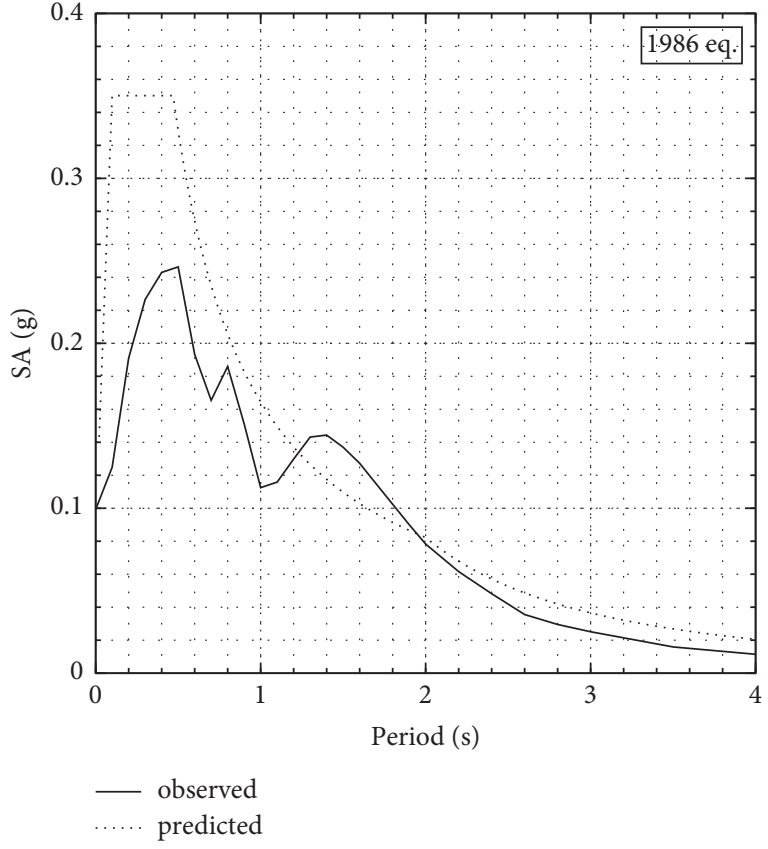

(b)

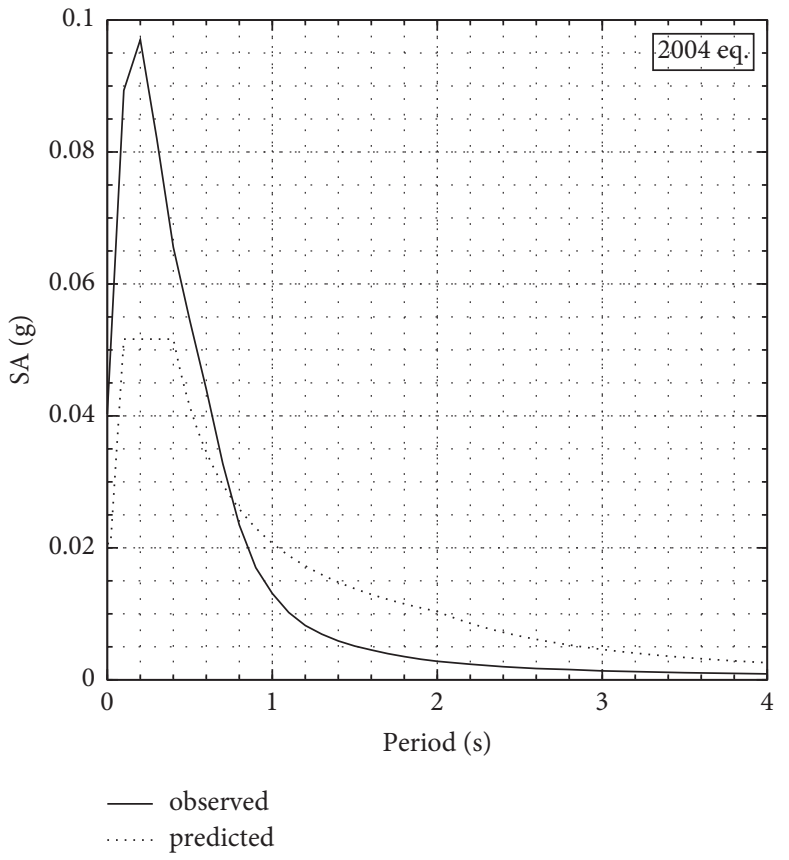

(d)

FIgURE 14: Comparison between the observed acceleration response spectra and the design response spectra according to the Eurocode 8 draft [30] for (a) 1977 earthquake; (b) 1986 earthquake; (c) 1990 earthquake; and (d) 2004 earthquake.

Table 4: Mean and standard deviation of the shear wave velocities in the upper $30 \mathrm{~m}$ and $50 \mathrm{~m}$ of soil deposits.

\begin{tabular}{lcc}
\hline Depth $(\mathrm{m})$ & Mean shear wave velocity $(\mathrm{m} / \mathrm{s})$ & Standard deviation of the shear wave velocity $(\mathrm{m} / \mathrm{s})$ \\
\hline 30 & 285 & 38 \\
50 & 314 & 33 \\
\hline
\end{tabular}


short-period spectral amplifications which were observed during smaller magnitude earthquakes. Thus, the current site amplifications proposed for the F site should be further revised and adapted for Bucharest in order to ensure the necessary level of seismic safety of new buildings.

\section{Conclusions}

This study is focused on the evaluation of the correlation and variability of ground motions recorded in Bucharest area. The correlation between the spectral accelerations and the peak ground velocity and displacement is evaluated based on a ground motion database of 119 pairs of horizontal components from 11 Vrancea intermediate-depth earthquakes. The statistics of the shear wave velocity up to a depth of $50 \mathrm{~m}$ are evaluated based on data collected from 41 boreholes. In addition, the correlation between the peak values of the ground motion and spectral acceleration ordinates on one hand and the earthquake magnitude on the other hand is also studied. An empirical model for the mean shear wave velocity up to $50 \mathrm{~m}$ as a function of the depth is proposed in this study. The main findings of this study can be summarized as follows:

The design spectral accelerations from the current code P100-/2013 [19] were exceeded in the short-period range by the spectral accelerations from the recorded ground motions. However, for the medium- and longperiod range, the spectral accelerations from the recorded ground motions are well below the current design ones.

A very good fit between the observed and the empirical peak ground velocities and displacements (computed from empirical spectral accelerations with the relations proposed in this study), with the exception of the $M_{\mathrm{W}}$ 7.1 1986 Vrancea earthquake.

A logarithmic fit for the mean shear wave velocity up to a depth of $50 \mathrm{~m}$ is proposed in this study. The variability in the shear wave velocities decreases with the depth of the soil profile.

The distribution of the shear wave velocities at a specific depth appears to follow a normal probability distribution.

Larger variabilities for the spectral accelerations computed for the seismic stations in Bucharest area were observed as compared to the variability of the peak ground velocity and displacement.

The variability in terms of shear wave velocities at specific depths is smaller than the variability of the spectral amplitudes of the recorded ground motions.

The design response spectra constructed according to the procedure given in the Eurocode 8 draft [30] fail to capture the long-period spectral amplifications occurring during large magnitude Vrancea intermediate-depth earthquakes and on the other hand fail to capture the significant short-period spectral amplifications which were observed during smaller magnitude earthquakes.

\section{Data Availability}

Data used in this study are available upon request to the author (e-mail: florin.pavel@utcb.ro).

\section{Conflicts of Interest}

The author declares that there are no conflicts of interest regarding the publication of this paper.

\section{Acknowledgments}

Funding for this research was ensured by the Ministry of National Education (MEN) through the Technical University of Civil Engineering Bucharest (UTCB) under grant number UTCB-CDI-2021-002. This support is gratefully acknowledged.

\section{References}

[1] E. F. Manea, C. Michel, M. Hobiger, D. Fäh, C. O. Cioflan, and M. Radulian, "Analysis of the seismic wavefield in the Moesian platform (Bucharest area) for hazard assessment purposes," Geophysical Journal International, vol. 210, no. 3, pp. 1609-1622, 2017.

[2] H. Sandi and I. S. Borcia, "A summary of instrumental data on the recent strong Vrancea earthquakes, and implications for seismic hazard," Pure and Applied Geophysics, vol. 168, no. 3-4, pp. 659-694, 2011.

[3] B. Grecu, M. Popa, and M. Radulian, "Seismic ground motion characteristics in the Bucharest area: sedimentary cover versus seismic source control," Romanian Reports in Physics n.d, vol. 55, pp. 322-331, 2003.

[4] A. Bala, C. Arion, and D. Toma, "Source effects of Vrancea earthquakes vs. Site effects recorded in bucharest city, Romania," in Proceedings of the 8th Congress of the Balkan Geophysical Society, pp. 1-5, Chania, Greece, October 2015.

[5] C. L. Moldoveanu and G. F. Panza, "Vrancea source influence on local seismic response in bucharest," Pure and Applied Geophysics, vol. 158, no. 12, pp. 2407-2429, 2001.

[6] W. Wirth, F. Wenzel, V. Y. Sokolov, and K.-P. Bonjer, “A uniform approach to seismic site effect analysis in Bucharest, Romania," Soil Dynamics and Earthquake Engineering, vol. 23, no. 8, pp. 737-758, 2003.

[7] F. Pavel, "Analysis of pulse-like ground motion recordings from Vrancea intermediate-depth earthquakes," Journal of Seismology, vol. 25, no. 2, pp. 733-745, 2021.

[8] P. Olteanu and R. Vacareanu, "Ground motion model for spectral displacement of intermediate-depth earthquakes generated by Vrancea seismic source," Geosciences, vol. 10, no. 8, p. 282, 2020.

[9] R. Vacareanu, M. Radulian, M. Iancovici, F. Pavel, and C. Neagu, "Fore-arc and back-arc ground motion prediction model for Vrancea intermediate depth seismic source," Journal of Earthquake Engineering, vol. 19, no. 3, pp. 535-562, 2015.

[10] CEN Eurocode 8, Design of Structures for Earthquake Resistance. Part 1: General Rules, Seismic Actions and Rules for Buildings, European Committee for Standardization, Bruxelles, Belgium, 2004.

[11] F. Pavel, V. Popa, and R. Vacareanu, Impact of Long-Period Ground Motions on Structural Design: A Case Study for 
Bucharest, Romania, Springer International Publishing, New York, NY, USA, 2018.

[12] F. Pavel, R. Vacareanu, K. Pitilakis, and A. Anastasiadis, "Investigation on site-specific seismic response analysis for Bucharest (Romania)," Bulletin of Earthquake Engineering, vol. 18, no. 5, pp. 1933-1953, 2020.

[13] R. Paolucci, M. Aimar, A. Ciancimino et al., "Checking the site categorization criteria and amplification factors of the 2021 draft of Eurocode 8 Part 1-1," Bulletin of Earthquake Engineering, vol. 19, no. 11, pp. 4199-4234, 2021.

[14] M. Radulian, N. Mândrescu, G. F. Panza, E. Popescu, and A. Utale, "Characterization of seismogenic zones of romania," in Seismic Hazard of the Circum-Pannonian Region, G. F. Panza, M. Radulian, and C.-I. Trifu, Eds., pp. 57-77, Birkhäuser, Basel, Switcherland, 2000.

[15] F. Pavel, R. Vacareanu, C. Cioflan, and M. Iancovici, "Spectral characteristics of strong ground motions from intermediatedepth Vrancea seismic source," Bulletin of the Seismological Society of America, vol. 104, no. 6, pp. 2842-2850, 2014.

[16] D. M. Boore and J. J. Bommer, "Processing of strong-motion accelerograms: needs, options and consequences," Soil Dynamics and Earthquake Engineering, vol. 25, no. 2, pp. 93-115, 2005.

[17] S. Akkar and J. J. Bommer, "Influence of long-period filter cutoff on elastic spectral displacements," Earthquake Engineering \& Structural Dynamics, vol. 35, no. 9, pp. 1145-1165, 2006.

[18] I. S. Borcia, Data Processing of strong Motion Records Obtained during Vrancea Earthquakes, Societatii Academice "Matei-Teiu Botez, Iasi, Romania, 2008.

[19] Mdrap, Code for Seismic Design-Part I-Design Prescriptions for Buildings, Springer International Publishing, New York, NY, USA, 2013.

[20] K. Kakderi and S. Argyroudis, "Fragility functions of water and waste-water systems," in SYNER-G: Typology Definition and Fragility Functions for Physical Elements at Seismic Risk: Buildings, Lifelines, Transportation Networks and Critical Facilities, K. Pitilakis, H. Crowley, and A. M. Kaynia, Eds., pp. 221-258, Springer, Berlin, Germany, 2014.

[21] F. Pavel and D. Lungu, "Correlations between frequency content indicators of strong ground motions and PGV," Journal of Earthquake Engineering, vol. 17, no. 4, pp. 543-559, 2013.

[22] J. J. Bommer and J. E. Alarcon, "The prediction and use of peak ground velocity," Journal of Earthquake Engineering, vol. 10, no. 1, pp. 1-31, 2006.

[23] E. Booth, "The estimation of peak ground-motion parameters from spectral ordinates," Journal of Earthquake Engineering, vol. 11, no. 1, pp. 13-32, 2007.

[24] P. K. Malhotra, "Smooth spectra of horizontal and vertical ground motions," Bulletin of the Seismological Society of America, vol. 96, no. 2, pp. 506-518, 2006.

[25] A. Bala, B. Grecu, V. Ciugudean, and V. Raileanu, "Dynamic properties of the Quaternary sedimentary rocks and their influence on seismic site effects. Case study in Bucharest City, Romania," Soil Dynamics and Earthquake Engineering, vol. 29, no. 1, pp. 144-154, 2009.

[26] A. Bala, V. Raileanu, I. Zihan, V. Ciugudean, and B. Grecu, "Physical and dynamic properties OF the shallow sedimentary rocks IN the bucharest metropolitan area," Romanian Reports in Physics, vol. 58, pp. 221-250, 2006.

[27] E. Calarasu, Microzonation of Local Soil Conditions for Bucharest and its Metropolitan Area with Applications for the Evaluation of Seismic Risk, Technical University of Civil Engineering Bucharest, Bucharest, Romania, 2012.
[28] E.-A. Călăraşu, C. Arion, and C. Neagu, Prediction of Site Characterization Based on Field Investigations and Empirical Correlations, The 1940 Vrancea Earthquake. Issues, Insights and Lessons Learnt, R. Vacareanu and C. Ionescu, Eds., pp. 151-168, Springer International Publishing, New York, NY, USA, 2016.

[29] D. Lungu, A. Aldea, T. Moldoveanu, V. Ciugudean, and M. Stefanica, Near-Surface Geology and Dynamic Properties of Soil Layers in Bucharest, Vrancea Earthquakes: Tectonics, Hazard and Risk Mitigation: Contributions from the First International Workshop on Vrancea Earthquakes, Bucharest, Romania, November 1-4, 1997, F. Wenzel, D. Lungu, and O. Novak, Eds., pp. 137-148, Springer, Berlin, Germany, 1999.

[30] CEN/TC 250/SC 8, Eurocode 8: Earthquake Resistance Design of Structures Work-Ing Draft 18 02.2021, CEN, Brussels, Belgium, 2021.

[31] N. A. Abrahamson, W. J. Silva, and R. Kamai, "Summary of the ASK14 ground motion relation for active crustal regions," Earthquake Spectra, vol. 30, no. 3, pp. 1025-1055, 2014. 